\title{
ADALIMUMAB FOR MAINTENANCE THERAPY FOR ONE YEAR IN CROHN'S DISEASE: results of a Latin American single-center observational study
}

\author{
Paulo Gustavo KOTZE¹, Vinícius Rezende ABOU-REJAILE'1, \\ Luciana Aparecida UIEMA ${ }^{1}$, Marcia OLANDOSKI $^{2}$, Maria Cristina SARTOR ${ }^{1}$, \\ Eron Fábio MIRANDA ${ }^{1}$, Lorete Maria da Silva KOTZE $^{3}$ and Rogério SAAD-HOSSNE ${ }^{4}$
}

\begin{abstract}
Context - Adalimumab is a fully-human antibody that inhibits TNF alpha, with a significant efficacy for long-term maintenance of remission. Studies with this agent in Latin American Crohn's disease patients are scarce. Objectives - The objective of this study was to outline clinical remission rates after 12 months of adalimumab therapy for Crohn's disease patients. Methods Retrospective, single-center, observational study of a Brazilian case series of Crohn's disease patients under adalimumab therapy. Variables analyzed: demographic data, Montreal classification, concomitant medication, remission rates after 1, 4, 6 and 12 months. Remission was defined as Harvey-Bradshaw Index $\leq 4$, and non-responder-imputation and last-observation-carried-forward analysis were used. The influence of infliximab on remission rates was analyzed by Fischer and Chi-square tests $(P<0.05)$. Results - Fifty patients, with median age of 35 years at therapy initiation, were included. Remission rates after 12 months of therapy were $54 \%$ under non-responder-imputation and $88 \%$ under last-observation-carried-forward analysis. After 12 months, remission on patients with previous infliximab occurred in $69.23 \%$ as compared to $94.59 \%$ in infliximab-naïve patients $(P=0.033)$. Conclusions - Adalimumab was effective in maintaining clinical remission after 12 months of therapy, with an adequate safety profile, and was also more effective in infliximab naïve patients.
\end{abstract}

HEADINGS - Tumor necrosis factor-alpha. Adrenergic alpha-antagonists, administration and dosage. Crohn disease, prevention and control.

\section{INTRODUCTION}

Crohn's disease $(\mathrm{CD})$ is an inflammatory, immune-mediated, incurable, chronic disease that requires medical and, occasionally, surgical treatment so as to remain under control ${ }^{(19,25)}$. It is caused by type 1 and 17 T-helper (Th1/Th17) alterations and an immune response pattern that includes increased production of interleukin 12, the tumor necrosis factor alpha (TNF- $\alpha$ ) and gamma interferon. TNF- $\alpha$ is a pro-inflammatory cytokine, and it plays a critical role in the disease's physiopathology ${ }^{(17,20)}$.

The incidence and prevalence of CD in Canada are among the highest in the world, and it is estimated that their respective rates are 13.4 and 233.7 cases in every 100,000 individuals a year ${ }^{(19)}$. Epidemiological data regarding Latin American patients are scarce. An estimation of CD prevalence in the state of São Paulo, Brazil, resulted in 5.65 cases in 100,000 inhabitants ${ }^{(26)}$.

Due to reduced efficacy and significant adverse effects of conventional drugs, new target therapy methods have been developed. Initially, infliximab (IFX) and, more recently, adalimumab (ADA) and certolizumab pegol, constitute what is referred to as biological therapy for $\mathrm{CD}$ management. These are TNF- $\alpha$ inhibitors that have significant efficacy in controlling the symptoms and the evolution of the disease $^{(4,9,22)}$.

ADA was the second biological agent approved worldwide for the treatment of $\mathrm{CD}$, and the experience with its use had increased over the years. Brazilian data concerning its use in CD management are scarce ${ }^{(13)}$. It is a recombinant monoclonal human antibody of immunoglobulin G1 that is subcutaneously administered with high affinity and specificity to TNF- $\alpha^{(5)}$. The clinical efficacy and safety of ADA in CD have been demonstrated in various clinical multi-center, randomized, double-blind, placebo-controlled trials, with distinction to CLASSIC I and II, CHARM and $\operatorname{GAIN}^{(5,10,20,21)}$, as well as in real life case series ${ }^{(24)}$.

${ }^{1}$ Unidade de Cirurgia Colorretal, Universidade Católica do Paraná; ${ }^{2}$ Disciplina de Bioestatística, Universidade Católica do Paraná, ${ }^{3}$ Unidade de Gastroenterologia, Universidade Católica do Paraná - PUCPR, Curitiba, PR, Brasil. ${ }^{4}$ Depatamento de Ciurgia Digestiva, Universidade de São Paulo, UNESP, Botucatu, SP, Brasil.

Correspondence: Paulo Gustavo Kotze. Rua Mauá, 682 - 80030-200 - Curitiba, PR, Brazil. E-mail: pgkotze@hotmail.com 
The scarcity of Latin American investigations evaluating the efficacy and safety of ADA in CD was one of the reasons for designing and developing this study. Therefore, the primary objective was to analyze clinical remission rates after 12 months of ADA therapy in a cohort of patients from a single reference center for inflammatory bowel diseases (IBD) management. Secondary objectives were to analyze remission rates after 1, 4 and 6 months of therapy, in addition to the patients' demographic profile, adverse events (AE), therapy discontinuation rates and the reasons for its occurence. Remission rates in relation to previous IFX use were also studied.

\section{METHOD}

This study was approved by the Research Ethics Committee of the Catholic University of Paraná (PUC-PR), with reference report number 108.623/12.

It was a longitudinal, analytical, observational and retrospective study on a case series of consecutive patients with CD diagnosis that used ADA as one of their forms of therapy. All the patients were managed and treated by the same unit's team from January 2008 to September 2012, and they comprised the only group of patients analyzed (no control group was defined).

The inclusion criteria for the study were: patients with $\mathrm{CD}$ aged 13 to 80 years that underwent ADA therapy in any phase of treatment for at least 2 months (completed induction regimen and 1 month of maintenance). The choice for age with a lower limit of 13 years is equivalent to that defined as the beginning of adolescence. All the patients included underwent the remission induction dose with 160 $\mathrm{mg}$ of ADA in week 0 and $80 \mathrm{mg}$ in week 2 , followed by 40 mg every 2 weeks for maintenance therapy. The exclusion criteria for this study were: patients with ulcerative colitis (UC) or indeterminate inflammatory bowel disease (IIBD) who were treated with ADA, patients with intestinal stomas (due to the difficulty of Harvey-Bradshaw Index [HBI] analysis), patients under 13 and over 80 years and those with less than 2 months of therapy or with a different dose regimen for induction of remission.

The variables analyzed were: gender, age at $\mathrm{CD}$ diagnosis, age at ADA therapy initiation, period of follow-up, disease duration at the beginning of biological therapy and form of disease presentation according to the Montreal Classification, in addition to the presence of perianal $\mathrm{CD}$. The concomitant use of other drugs, such as corticosteroids (CS) and azathioprine (AZA), and smoking status, were also evaluated. The main variable studied was the occurrence of clinical remission 12 months after ADA therapy. Remission rates were also analyzed after 1, 4 and 6 months. Other variables analyzed were the presence of $\mathrm{AE}$, therapy discontinuation and the reasons for its occurrence.

Clinical data were collected by means of electronic chart review. In case of lacking data on the charts, telephone calls were made to patients whenever needed to complement the information.

Efficacy analysis was evaluated by HBI, and clinical remission was defined as an $\mathrm{HBI} \leq 4^{(11)}$. In patients with fistulizing perianal $\mathrm{CD}$, remission was also defined by $\mathrm{HBI} \leq 4$. However, response was also defined as absence of drainage after therapy, without formation of perianal abscess during follow-up.

The non-responder-imputation (NRI) and last-observation- carried-forward (LOCF) methods were used for clinical remission analysis. In the NRI method, patients with a shorter follow-up time were considered to be without remission in the later periods of analysis. On the other hand, in the LOCF evaluation, the lastly evaluated information was carried forward, and it served as a value for the subsequent periods. These methods were used due to the fact that some patients had a follow-up period that was shorter than 12 months. AE were observed from the first ADA dose until each patient's last recorded visit during the use of the medication.

Data were analyzed by simple description using frequency tables, in addition to confidence intervals (CI). In order to evaluate clinical remission rates in relation to previous IFX exposure, Fisher's exact test and the chi-square test were used, and $P$ values $<0.05$ indicated statistical significance. For each of the evaluation points (1, 4, 6 and 12 months), the null hypothesis that remission probability was similar for patients with previous IFX administration and patients naïve to anti-TNF agents, versus the alternative hypothesis of different probabilities was tested. An inverted Kaplan-Meier plot with multivariate and Cox regression analysis were also used for the evaluation of remission of all patients, according to their previous IFX status. Data were analyzed by using the Statistica v.8.0 software package.

\section{RESULTS}

In the study period, from January 2008 to September 2012, 57 patients were treated with ADA. Of these, 4 were excluded for not completing the minimum 2-month follow-up period (they just had their first ADA administration of 160 $\mathrm{mg}$ at the evaluation for the study), and 3 were excluded due to the presence of ileostomies, which would hinder analysis of the HBI score. Therefore, for general analysis, 50 patients were studied. After induction, ADA therapy proceeded with 40 mg every two weeks; nevertheless, not all patients completed 12 months of therapy. Forty-five patients achieved 4 months of ADA treatment; 41 were treated for up to 6 months, and 32 patients completed the 12 months of treatment. From the 18 patients that did not have a follow-up for 12 months, all of them started ADA therapy more recently. None of them were lost of follow-up.

According to the Montreal classification, regarding the age at diagnosis, the most prevalent group was A2 (17 - 40 years) with $34(68 \%)$ patients. Regarding the disease location, 29 (58\%) patients presented with L3 (ileocolic CD). Concerning disease behavior, group B3 (penetrating CD) predominated, with $38(76 \%)$ patients. CD perianal involvement was observed in $39(78 \%)$ cases. All patients that had concomitant immunomodulators used azathioprine. No patients previously had 6-mercaptopurine or methotrexate therapy. 
Regarding the indication for ADA therapy, 39 (78\%) of the patients used the medication for perianal fistulizing $\mathrm{CD}$, and the other $11(22 \%)$ for failure to medical therapy and dependency on steroids.

The baseline characteristics of all analyzed patients, according to their previous status of IFX exposure, are described in Table 1.

In relation to the remission rates, in LOCF analysis, after 1 month of ADA therapy, it was observed in 39 of the 50 patients in the study, representing $78 \%$ of the cases (CI 95\%: 0.665-0.895). Four months after the beginning of therapy, 40 $(80 \%)$ patients were in clinical remission, and after 6 months, $41(82 \%)$ patients (CI 95\% 0.689-0.911 and 0.714-0.926, respectively). After 12 months from the beginning of ADA therapy, 44 patients $(88 \%)$ were in clinical remission (CI 95\% $0.790-0.970)$. By taking into account the NRI evaluation, clinical remission rates were slightly different. One month after ADA initiation, the rate was the same as that found in the previous evaluation (78\%). Four months after therapy initiation, 35 of the 50 patients were in clinical remission, which represented $70 \%$ of the patients (CI 95\% 0.573-0.827). At 6 months of therapy, that number decreased to $32(64 \%)$ patients, (CI 95\% 0.507-0.773), and at 12 months, the remission rate in the group decreased to 27 patients, corresponding to $54 \%$ of the cases (CI 95\% 0.402-0.678). These data are demonstrated in Figure 1.

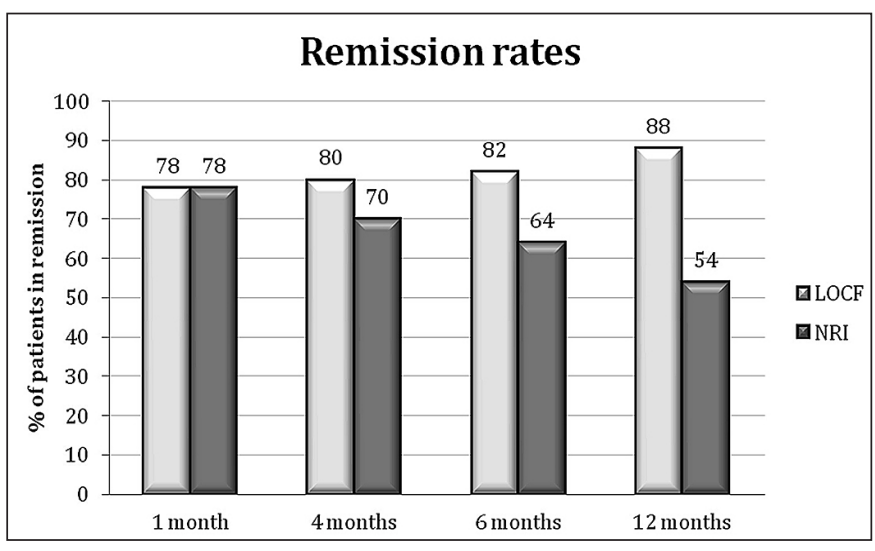

FIGURE 1. Remission rates at moments 1, 4, 6 and 12 months after the therapy initiation with adalimumab (ADA). LOCF: last-observation-carried-forward analysis; NRI: non-responder- imputation analysis.

According to the previous IFX-exposure status, the results were obtained following analysis by the NRI and LOCF methods. From the 13 patients with previous IFX therapy, 9 started ADA after secondary loss of response to IFX, and 4 because of severe infusion reactions. It was observed that there was a statistically significant difference only in the period of 12 months after the beginning of ADA therapy, when evaluated by the LOCF method. The results obtained

TABLE 1. Baseline characteristics from the patients included in the analysis, regarding their status to previous IFX exposure.

\begin{tabular}{|c|c|c|c|c|}
\hline Characteristic & $\begin{array}{l}\text { Overall } \\
(\mathrm{n}=50)\end{array}$ & $\begin{array}{c}\text { No previous IFX } \\
(\mathrm{n}=37)\end{array}$ & $\begin{array}{l}\text { Previous IFX } \\
\quad(\mathrm{n}=13)\end{array}$ & $P$ value* \\
\hline Age at diagnosis & $29.0 \pm 13.1$ & $30.1 \pm 12.0$ & $25.8 \pm 15.9$ & 0.308 \\
\hline Age at ADA initiation & $35.0 \pm 13.1$ & $35.8 \pm 12.7$ & $33.0 \pm 14.5$ & 0.519 \\
\hline Male gender & $27(54.0)$ & $22(59.5)$ & $5(38.5)$ & 0.215 \\
\hline Disease duration $>24$ months & $25(50.0)$ & $16(43.2)$ & $9(69.2)$ & 0.196 \\
\hline Disease duration at ADA therapy initiation (months) & $73.6(1-312)$ & $18(1-312)$ & $60(18-204)$ & 0.060 \\
\hline Follow-up period (months) & $13.5(2-84)$ & $12(2-48)$ & $28(13-84)$ & $<0.001$ \\
\hline \multicolumn{5}{|l|}{ Montreal } \\
\hline A1 (16 years or less) & $6(12.0)$ & $2(5.4)$ & $4(30.8)$ & \\
\hline A2 (17 - 40 years $)$ & $34(68.0)$ & $28(75.7)$ & $6(46.7)$ & \\
\hline A3 (over 40 years) & $10(20.0)$ & $7(18.9)$ & $3(23.1)$ & 0.039 \\
\hline L1 (small bowel) & $11(22.0)$ & $10(27.0)$ & $1(7.7)$ & \\
\hline L2 (colon) & $10(20.0)$ & $5(13.5)$ & $5(38.5)$ & \\
\hline L3 (ileocolic) & $29(58.0)$ & $22(59.5)$ & $7(53.8)$ & 0.096 \\
\hline B1 (non-stenosing/non-penetrating) & $6(12.0)$ & $6(16.2)$ & $0(0)$ & \\
\hline B2 (stenosing) & $6(12.0)$ & $6(16.2)$ & $0(0)$ & \\
\hline B3 (penetrating) & $38(76.0)$ & $25(67.6)$ & $13(100)$ & - \\
\hline Perianal CD & $39(78.0)$ & $26(70.3)$ & $13(100)$ & 0.046 \\
\hline Smoking & $3(6.0)$ & $3(8.1)$ & $0(0)$ & 0.558 \\
\hline Concomitant AZA & $42(84.0)$ & $30(81.1)$ & $12(92.3)$ & 0.662 \\
\hline Steroids at initiation of $\mathrm{ADA}$ & $21(42.0)$ & $14(37.8)$ & $7(53.8)$ & 0.346 \\
\hline Previous abdominal operations & $24(48.0)$ & $17(45.9)$ & $7(53.8)$ & 0.751 \\
\hline
\end{tabular}

* Continous variables: mean \pm standard deviation and Student's $t$ test or median (min-max) and Mann-Whitney test. Categorical variables: frequency (percentages) and Chi-square test or Fishe exact test. ADA: adalimumab; IFX: infliximab 
are detailed in Table 2. When evaluated by multivariate analysis and Cox regression analysis, considering the whole 12-month period, no statistical significance was found $(P=$ 0.148 ), as demonstrated in Figure 2. No patients in this study were previously treated with Certolizumab Pegol.

Fistulizing perianal $\mathrm{CD}$ was found in 38 patients. A single patient had non-fistulizing perianal CD. A specific analysis

TABLE 2. Evaluation of the association between previous infliximab (IFX) use for each moment in relation to adalimumab (ADA). Analysis by the non-responder-imputation (NRI) and last-observation- carried-forward (LOCF) methods, with statistical analysis by the Fischer and Chi-square methods $(P<0.05)$, with $(*)$ as statistical significance.

\begin{tabular}{|c|c|c|c|}
\hline & \multicolumn{2}{|c|}{ Previous IFX } & \multirow{3}{*}{$\begin{array}{c}P \text { value } \\
--\end{array}$} \\
\hline & No & Yes & \\
\hline Patients, $\mathrm{n}$ & 37 & 13 & \\
\hline \multicolumn{4}{|c|}{ Remission-1 month (NRI) } \\
\hline No, n $(\%)$ & $9(24.32)$ & $2(15.38)$ & \multirow{2}{*}{0.704} \\
\hline Yes, n (\%) & $28(75.68)$ & $11(84.62)$ & \\
\hline \multicolumn{4}{|c|}{ Remission-1 month (LOCF) } \\
\hline No, n $(\%)$ & $9(24.32)$ & $2(15.38)$ & \multirow{2}{*}{0.704} \\
\hline Yes, n (\%) & $28(75.68)$ & $11(84.62)$ & \\
\hline \multicolumn{4}{|c|}{ Remission-4 months (NRI) } \\
\hline No, n $(\%)$ & $13(35.14)$ & $2(15.38)$ & \multirow{2}{*}{0.294} \\
\hline Yes, n (\%) & $24(64.86)$ & $11(84.62)$ & \\
\hline \multicolumn{4}{|c|}{ Remission- 4 months (LOCF) } \\
\hline No, n $(\%)$ & $8(21.62)$ & $2(15.38)$ & \multirow{2}{*}{1.000} \\
\hline Yes, n (\%) & $29(78.38)$ & $11(84.62)$ & \\
\hline \multicolumn{4}{|c|}{ Remission-6 months (NRI) } \\
\hline No, n (\%) & $14(37.84)$ & $4(30.77)$ & \multirow{2}{*}{0.746} \\
\hline Yes, n (\%) & $23(62.16)$ & $9(69.23)$ & \\
\hline \multicolumn{4}{|c|}{ Remission-6 months (LOCF) } \\
\hline No, n $(\%)$ & $5(13.51)$ & $4(30.77)$ & \multirow{2}{*}{0.214} \\
\hline Yes, n (\%) & $32(86.49)$ & $9(69.23)$ & \\
\hline \multicolumn{4}{|c|}{ Remission-12 months (NRI) } \\
\hline No, n $(\%)$ & $19(51.35)$ & $4(30.77)$ & \multirow{2}{*}{0.332} \\
\hline Yes, n (\%) & $18(48.65)$ & $9(69.23)$ & \\
\hline \multicolumn{4}{|c|}{ Remission-12 months (LOCF) } \\
\hline No, n $(\%)$ & $2(5.41)$ & $4(30.77)$ & \multirow{2}{*}{$0.033^{*}$} \\
\hline Yes, n $(\%)$ & $35(94.59)$ & $9(69.23)$ & \\
\hline
\end{tabular}

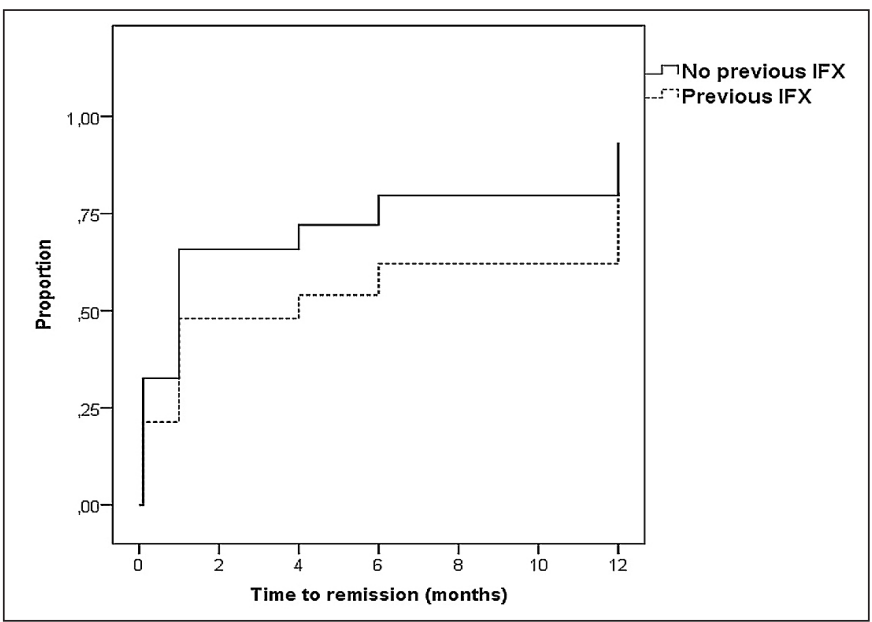

FIGURE 2. Inverted Kaplan-Meier plot comparing remission in patients regarding their previous exposure to infliximab (IFX) during the 12 month period. Multivariate analysis with Cox regression $(P=0.148)$ on the patients with fistulizing $\mathrm{CD}$ demonstrated that 20 of them $(52,6 \%)$ had abscence of perianal drainage during follow-up (defined as response), and 18 of these patients still had perianal drainage at last visit. No patients with abdominal fistulizing $\mathrm{CD}$ were observed in this case series.

AE occurred in 8 of the $50(16 \%)$ patients. The total number of $\mathrm{AE}$ was 15, and 2 patients had $2 \mathrm{AE}$ each; 1 patient had $3 \mathrm{EA}$, and 1 patient had 4 described events. The most common $\mathrm{AE}$ found in this series was topical allergic reaction (five cases), and headache was described on two occasions. Only one severe AE was found (herpes zoster infection). Eye oedema, hand oedema, arthralgia, severe cold, low fever, nausea and alopecia occurred in one patient each.

ADA therapy discontinuation occurred in $12(24 \%)$ patients, and the AE (herpes zoster infection) was the cause for that in only one case. In another patient, loss of response to the medication occurred, and the therapy was interrupted by complications (need for abdominal surgery due to $C D$ progression). In three patients, ADA was discontinued as the patient's option (travelling abroad), even without medical advice, and seven patients discontinued the treatment because they lost access to the drug's provision by the public health care system. The single patient that presented with secondary loss of response to ADA was a patient who already had loss of response to IFX. This patient, who was using steroids at the beginning of the study, was treated again with oral steroids, as optimization of ADA to $40 \mathrm{mg}$ weekly was not reimbursed in our country. The remaining 20 patients that were on steroids at ADA initiation did not need steroids as a rescue therapy up to their last visit in this study.

Surgical treatment occurred in $23(46 \%)$ of patients during ADA therapy. In some patients, more than one procedure was needed. The majority of the procedures performed were examinations under anesthesia with seton placement (15/23 patients). Regarding abdominal operations for CD, five patients were submitted to ileocecal resections, one with associated small bowel resection and three developed perianal abscesses that needed drainage. From the five patients submitted to abdominal resections for $\mathrm{CD}$, two developed surgical site simple infections. No major surgical complications or infections, as pneumonia or from the urinary tract, occurred in these cases.

\section{DISCUSSION}

$\mathrm{CD}$ is a chronic inflammatory disease that presents periods of clinical remission between periods of recurrent inflammatory activity. CD medical management has been the object of various discussions in the last few years, and it is currently established, both in a national consensus published by GEDIIB (Brazilian study group for IBD) and in other worldwide gudelines ${ }^{(2)}$.

ADA therapy is addressed in these guidelines, considering that its approval for CD management occured in 2007. Since then, the experience with this drug had increased worldwide, and studies from several countries have been published and shown its efficacy and safety profile. This is one of the first studies to be performed on Latin American patients with ADA in CD. The only Brazilian study that evaluated ADA in 
CD was published in 2011. It was a retrospective multi-center study on efficacy evaluation after a 4-week therapy in 54 patients. After the induction regimen, 26 (48.14\%) patients were in clinical remission; $26(48.14 \%)$ patients demonstrated partial response and only $2(3.72 \%)$ were primary non-responders ${ }^{(13)}$. This previous study did not use any objective index to check remission rates, as the HBI or the CDAI, only based the results in the physician global accessment (PGA).

The mean CD duration at the beginning of ADA treatment, regardless of previous IFX use, was 73.6 months. This period is a little shorter when compared to that in the results recently published in the CARE trial, which was 7.8 years (93.6 months) ${ }^{(16)}$. The shorter disease duration at therapy initiation may be explained by the fact that the present study was developed with patients treated by colorectal surgeons, physicians with more referrals of patients with extensive intestinal ulcerations and fistulas, who had undergone multiple operations or with perianal fistulizing $\mathrm{CD}$, which characterizes a more aggressive phenotype of the disease. Additionally, the top-down (descending) strategy was used in some cases, which preconizes that the early use of biologicals can be beneficial in selected cases. The staff from our unit occasionally approaches patients by the top-down strategy, based on the study published by D' Haens et al. in 2008, which compared the two strategies and demonstrated some promising results with the early use of biological therapy ${ }^{(6)}$. Among the patients that were treated with this therapy strategy are those with previous abdominal surgery, who represented $48 \%$ of the total sample, what can explain the proportion of early use of biological therapy commencement in the present study.

Smoking is a known factor that leads to a worse prognosis for $\mathrm{CD}^{(3)}$, and it was found in only 3 of the $50(6 \%)$ patients in the present study. This percentage is smaller than those in the literature, which range from $14 \%$ to $37 \%$ of the patients ${ }^{(5,12,24)}$. Such finding can be justified by a current tendency of the Brazilian culture to reduce smoking by means of population-awareness development campaigns, in addition to the broad dissemination in non-medical websites that show the clear association of smoking with a worse prognosis for CD patients.

Corticosteroids (CS) are efficient in inducing remission in $60 \%$ to $93 \%$ of CD patients ${ }^{(15,18)}$. However, its toxicity and low capacity to maintain remission are still reasons for concern $^{(23)}$. The early need for steroids to control symptoms may be a negative prognostic marker for CD outcomes ${ }^{(1,8)}$. In the present study, the concomitant use of CS at the beginning of ADA therapy was observed in $42 \%$ of the sample. This information follows the tendency of other published studies, which range from $42 \%$ to $55 \%$ of patients ${ }^{(5,13,24)}$.

The biological therapy combined with AZA was observed in $84 \%$ of the patients included in the present study. This information agrees with that in the only national study on the subject, published in 2011, in which Kotze et al., in a multi-center study, described that $88.9 \%$ of patients undergoing induction to clinical remission with ADA in $\mathrm{CD}$ concomitantly were treated with $\mathrm{AZA}^{(13)}$. In other international studies, combination therapy with two drugs is observed in approximately $42 \%$ to $44 \%$ of cases $^{(5,24)}$. In 2010 , the SONIC trial demonstrated superiority of the IFX therapy combined with AZA in relation to the patients that were under either IFX or AZA as monotherapies ${ }^{(4)}$. Furthermore, that study did not show higher infection rates in the group using combined therapy. Since its publication, most of the reference centers for IBD management have preferably used the combination strategy. Although there are no controlled studies with ADA that compared combination versus monotherapy, the combination strategy may be transposed to ADA, similarly to the way in which IFX is combined with immunomodulators, by questioning a class effect among TNF- $\alpha$ inhibitors. This is probably the explanation for the large number of patients undergoing combined therapy in the present study. Moreover, before the SONIC study, all subanalysis from IFX trials also did not demonstrate better efficacy in combination therapy with immunomodulators ${ }^{(9)}$. Until a prospective trial is published, with a design similar to SONIC's, including ADA patients, the controversy regarding combination therapy with ADA will still persist.

Ileocolic involvement (L3), occurred in $58 \%$ of the patients in the present study. This data was similar to that in the study by the Mayo Clinic, which was $64 \%$. Penetrating CD (B3) and perianal involvement occurred in $76 \%$ and $78 \%$ of the patients, respectively, in the present study. These rates are higher than those observed in the American study in which $21 \%$ of the patients had active fistulae, whether perianal, rectovaginal or enterocutaneous. Additionally, perianal involvement in this study was only $32 \%{ }^{(24)}$. Since our study was carried out in a surgical unit, this can explain the high rates found for penetrating disease and perianal involvement. Many patients were referred from other units by clinical gastroenterologists, particularly for the management of fistulizing perianal CD.

The clinical remission rates in the present study with 1 and 12 months, by taking into account the NRI analysis, were $78 \%$ and $54 \%$, respectively. These rates are higher than those in randomized, double-blind placebo-controlled studies. Within 4 weeks, the remission rates in the CLASSIC I and GAIN trials for ADA-treated patients at a dose of 160/80 mg were $36 \%$ and $21 \%$, respectively ${ }^{(10,21)}$. In the CHARM trial, which lasted 1 year, remission occurred in $36 \%$ of the sample ${ }^{(5)}$. The major requirements of a randomized and controlled study clearly contributed to this difference, since there is a tendency to lower figures in pivotal studies due to more strict analysis.

On the other hand, when comparing the findings in the present study with ADA efficacy in open-labeled studies, the numbers were similar. In the CARE trial, which included naïve patients and those previously treated with IFX, the general clinical remission rate with approximately 5 months was $52 \%$ (CI 95\% $0.49-0.55)^{(16)}$. These figures from open-labeled studies and from patient cohorts were similar to those found in the present study.

In the present study, previous IFX use did not influence clinical remission rates with ADA in the analyzed periods of 1,4 and 6 months, regardless of the method of analysis. The only statistically significant difference was found in the analysis after 12 months, when analyzed by LOCF method. In this situation, the remission rate observed in patients previously 
treated with IFX was lower than in those without previous treatment $(69.23 \%$ versus $94.59 \%$, respectively, $P=0.033$ ). On the other hand, multivariate Cox regression analysis, considering remission during all periods of the study continuously, did not demonstrate significant difference between the groups $(P$ $=0.148)$. The higher clinical remission rates in anti-TNF naïve patients also occurred in the CARE trial $(62 \%$ versus $42 \%$, $P<0.001)^{(16)}$. Data from the GAIN trial demonstrated that patients previously treated with IFX had lower remission rates than did IFX-naïve individuals from the CLASSIC I trial ${ }^{(21)}$.

The high rates of clinical remission found in the present data can be explained by the already known limitations of a retrospective study. The HBI used to evaluate clinical remission is based on subjective information, and the absolute value may suffer variations. The number of episodes of diarrhea greatly influences the final HBI score, which may cause patients that have active disease to show an important reduction in that index after the decrease in the number of liquid stools per day. That would give the false impression that the patient had achieved clinical remission. Moreover, patients with fistulizing perianal $\mathrm{CD}$, can have a low $\mathrm{HBI}$ index even with persistence of drainage. HBI was used as a marker to evaluate clinical remission in the present study due to its simple and practical measurement. Due to the difficulty in measuring diarrhea and HBI calculation, three patients with ileostomies were excluded from the study. Another contribution to the high clinical remission rates is the fact that this study is the result of a real life cohort in which the methodology requirements for patient inclusion and for data collection are not strict as in prospective pivotal trials.

The NRI and LOCF methods were selected as forms of analysis due to the loss of patients in some evaluation periods in the study, especifically 12 months after ADA introduction. It is considered that the NRI method demonstrates more reliable results due to its greater requirements (a more conservative analysis).

During the 12-month period after ADA introduction in the present study, $15 \mathrm{AE}$ were observed in a total of $8(16 \%)$ patients. The small percentage of patients who developed AE can be explained by the limitation of the retrospective methodology, since such events may not be recorded on patients' charts, and the spontaneous resolution of simpler events my occur without the patients reporting them to the physicians at some consultations. The short follow-up period can be also pointed as a reason for the low AE rates in this series.

The most common AE was allergic reaction on the injection site in $10 \%$ of the patients $(5 / 50)$, as shown in most of the studies with ADA. The only severe AE leading to ADA treatment discontinuation was the onset of a herpes zoster infection in a single patient. No cases of malignancy or deaths were observed. The low severe AE rate was probably favored by the patients' detailed evaluation routine prior to biological therapy initiation.

Short-term safety analysis in the CLASSIC I and GAIN trials demonstrated similar AE rates. The most frequent $\mathrm{AE}$ was allergic reaction on the injection site with higher incidence in patients using the $160 / 80 \mathrm{mg}$ dose $(36 \%)$ as compared to $16 \%$ in the placebo group, whereas on the injection site in the second study, the frequency of reaction was similar in the two groups (10\% versus $11 \%)$. The occurrence of severe $\mathrm{AE}$ was rare and similar in the actively treated group and in the placebo group ${ }^{(10,21)}$. By comparing the results obtained in the present study to those in randomized studies, it is noted that mild AE rates were lower than those reported in the literature and that severe infections, malignancy and deaths are rare events with ADA treatment in CD.

This study had clear limitations, particularly due to the fact that it was a retrospective study with a small sample. Moreover, patients with previous IFX exposure had higher incidence of perianal CD and a longer follow-up period. Another limitation is that it was performed at a reference center for colorectal surgery, therefore, with higher prevalence of fistulizing $\mathrm{CD}$ among the analyzed cases. Additionally, many patients (18) did not complete the 12 months period needed for a full evaluation. In these cases, the use of the NRI and LOCF methods, as well as the inverted Kaplan-Meier plot, may have contributed to the estimated results.

In summary, ADA therapy resulted in significant rates of CD clinical remission, reaching $54 \%$ of the patients after 12 months of therapy according to the NRI analysis and $88 \%$ according to the LOCF analysis. Clinical remission rates after 1, 4, and 6 months of therapy with the drug showed significant ADA efficacy regardless of the analysis used, and these data were similar to the literature. The mean disease duration at therapy initiation was 73.6 months, and most patients used ADA in combination to azathioprine. AE were observed in only $16 \%$ of the patients, and only one event was considered to be severe. The main cause for ADA discontinuation was the loss of access to the drug in the public health care system. The remission rates observed in patients with prior IFX therapy were lower than in those without previous exposure before ADA initiation.

The importance of the findings in the present study, that must be interpreted with caution, is based on the fact that they constitute the first experience with ADA in the maintenance therapy for CD management in Latin American patients.

\section{ACKNOWLEDGEMENTS}

The authors would sincerely acknowledge professor Marcia Olandoski (Catholic University of Parana) for the statistical analysis, and Luciana Aparecida Uiema (Catholic University of Parana) for the support during data collection.

\section{Disclosure}

Paulo Gustavo Kotze, Lorete Maria da Silva Kotze and Rogerio Saad-Hossne are speakers for Abbott laboratories. Paulo Gustavo Kotze, Eron Fabio Miranda and Rogerio Saad-Hossne are speakers for Janssen-Cilag. Paulo Gustavo Kotze is also speaker for Takeda and Astrazeneca, and gave consultancy for Pfizer. The other authors have no conflicts of interest.

\section{Authorship}

Paulo Gustavo Kotze and Vinicius Abou-Rejaile designed 
the study. Paulo Gustavo Kotze, Vinicius Abou-Rejaile, Luciana Aparecida Uiema, Maria Cristina Sartor, Eron Fabio Miranda and Lorete Maria da Silva Kotze collected the data. Marcia Olandoski did the statistical analysis. Paulo Gustavo Kotze, Lorete Maria da Silva Kotze and Rogerio
Saad-Hossne wrote the article and all authors reviewed it and gave full authorization for this publication.

\section{Funding source}

This study had no funding source.

Kotze PG, Abou-Rejaile VR, Uiema LA, Sartor MC, Miranda EF, Kotze LMS, Olandoski M, Saad-Hossne R. Adalimumabe na terapia de manutenção por um ano na doença de Crohn: resultados de um estudo observacional unicêntrico Latinoamericano. Arq Gastroenterol. 2014,51(1):39-45.

RESUMO - Contexto - O adalimumabe é um anticorpo monoclonal totalmente humano que inibe o TNF alfa, com eficácia documentada na manutenção da remissão clínica na doença de Crohn. Estudos com pacientes latinoamericanos são escassos nesse cenário. Objetivo - O objetivo deste estudo foi analisar as taxas de remissão clínica após 12 meses de terapia com adalimumabe em portadores de doença de Crohn. Método - Estudo retrospectivo unicêntrico observacional de uma série de casos de pacientes brasileiros portadores de doença de Crohn tratados com adalimumabe. Variáveis analisadas: dados demográficos, classificação de Montreal, medicações concomitants, taxas de remissão após 1, 4, 6 e 12 meses. Remissão foi definida como índice de Harvey-Bradshaw $\leq 4$ e foram utilizadas as análises de imputação de não-resposta e última observação considerada. A influência do infliximab prévio foi analisada pelo teste de Fischer e qui-quadrado $(P<0.05)$. Resultados - Cinquenta pacientes, com media de idade de 35 anos no início da terapia foram incluídos. As taxas de remissão após um ano foram de 54\% (análise imputação de não-resposta) e 88\% (análise de última observação considerada. A remissão clínica ocorreu em $69.23 \%$ dos pacientes com infliximab prévio e $94.59 \%$ nos virgens de infliximab $(P=0.033)$. Conclusões - O adalimumabe foi efetivo na manutenção da remissão clínica após 1 ano, com adequado perfil de segurança com eficácia maior nos pacientes virgens de infliximab.

DESCRITORES - Fator de necrose tumoral alfa. Antagonistas adrenérgicos alfa, administração e dosagem. Doença de Crohn, prevenção e controle.

\section{REFERENCES}

1. Beaugerie L, Seksik P, Nion-Larmurier I, Gendre JP, Cosnes J. Predictors of Crohn's disease. Gastroenterology. 2006;130:650-6.

2. Brazilian Study Group of Inflammatory Bowel Diseases. Consensus guidelines for the management of inflammatory bowel disease. Arq Gastr. 2010;47:313-25.

3. Calkins BM. A meta-analysis of the role of smoking in inflammatory bowel disease. Dig Dis Sci. 1989;34:1841-54.

4. Colombel JF, Sandborn WJ, Reinisch W, Mantzaris GJ, Kornbluth A, Rachmilewitz D, LIchtiger S, D’Haens G, Diamond RH, Broussard DL, Tang KL, van der Woude J, Rutgeerts P, for the SONIC study group. Infliximab, Azathioprine, or Combination Therapy for Crohn's Disease. N Engl J Med. 2010;362:1383-95.

5. Colombel JF, Sandborn WJ, Rutgeerts P, Enns R, Hanauer SB, Panaccione R, Schreiber S, Byczkowski D, Li J, Kent JD, Pollack PF. Adalimumab for maintenance of clinical response and remission in patients with Crohn's disease: the CHARM trial. Gastroenterology. 2007;132:52-65.

6. D'Haens G, Baert F, van Assche G, Caenepeel P, Vergauwe P, Tuynman H, de Vos M, van Deventer S, Stitt L, Donner A, Vermeire S, de Mierop FJ, Coche JR, van der Woude J, Ochsenkuhn T, van Bodegraven AA, Van Hootegem PP, Lambrecth GL, Mana F, Rutgeerts P, Feagan BG, Hommes D. Early combined immunosuppression or conventional management in patients with newly diagnosed Crohn's disease: an open randomised trial. Lancet. 2008;371:660.

7. Eugene C. The second European evidence-based Consensus on the diagnosis and management of Crohn's disease. Clin Res Hepatol Gastroenterol. 2011;35:257-9.

8. Faubion WA Jr, Loftus EV Jr, Harmsen WS, Zinsmeister AR, Sandborn WJ. The natural history of corticosteroid therapy for inflammatory bowel disease: a population-based study. Gastroenterology. 2001;121:255-60.

9. Hanauer SB, Feagan BG, Lichtenstein GR, Mayer LF, Schreiber S, Colombel JF, Rachmilewitz D, Wolf DC, Olson A, Bao W, Rutgeerts P. Maintenance infliximab for Crohn's disease: the ACCENT I randomised trial. Lancet. 2002;359:1541-9.

10. Hanauer SB, Sandborn WJ, Rutgeerts P, Fedorak RN, Lukas M, MacIntosh D Panaccione R, Wolf D, Pollack P. Human anti-tumor necrosis factor monoclonal antibody (adalimumab) in Crohn's disease: the CLASSIC-I trial. Gastroenterology. 2006; 130:323-33.

11. Harvey RF, Bradshaw JM. A simple index of Crohn's-disease activity. Lancet. 1980;1:514.

12. Kamm MA, Hanauer SB, Panaccione R, Colombel JF, Sandborn WJ, Pollack PF, Zhou Q, Robinson AM. Adalimumab sustains steroid-free remission after 3 years of therapy for Crohn's disease. Aliment Pharmacol Ther. 2011;34:306-17.

13. Kotze PG, Vieira A, Junior SCW, Salem JB, Kotze LMS. Adalimumab in the induction of Crohn's disease remission: results of a Brazilian multicenter case series. Rev Bras Coloproct. 2011;31:233-240.

14. Landi B, Anh TN, Cortot A, Soule JC, Rene E, Gendre JP, Bories P, See A, Metman EH, Florent $\mathrm{C}$ et al. Endoscopic monitoring of Crohn's disease treatment: a prospective, randomized clinical trial. The Groupe d'Etudes Therapeutiques des Affections Inflammatoires Digestives. Gastroenterology. 1992;102:1647-53.
15. Lichtenstein GR, Abreu MT, Cohen R, Tremaine W. American Gastroenterological Association Institute medical position statement on corticosteroids, immunomodulators, and infliximab in inflammatory bowel disease. Gastroenterology. 2006;130:935-9.

16. Lofberg R, Louis EV, Reinisch W, Robinson AM, Kron M, Camez A, Pollack PF. Adalimumab Produces Clinical Remission and Reduces Extraintestinal Manifestations in Crohn's Disease: Results from CARE. Inflamm Bowel Dis. 2012;18:1-9.

17. Miheller P, Lakatos PL, Horváth G, Molnár T, Szamosi T, Czeglédi Z, Salamon A, Czimmer J, Rumi G, Palatka K, Papp M, Jakab Z, Szabó A, Gelley A, Lakatos L, Barta Z, Balázs C, Rácz I, Zeher M, Döbrönte Z, Altorjay I, Hunyady B, Simon L, Papp J, Banai J, Nagy F, Lonovics J, Ujszászy L, Muzes G, Herszényi L, Tulassay Z. Efficacy and safety of infliximab induction therapy in Crohn's Disease in Central Europe - a Hungarian nationwide observational study. BMC Gastroenterol. 2009;9:66.

18. Munkholm P, Langholz E, Davidsen M, Binder V. Frequency of glucocorticoid resistance and dependency in Crohn's disease. Gut. 1994;35:360-2.

19. Panaccione R, Loftus EV Jr, Binion D, McHugh K, Alam S, Chen N, Guerette B, Mulani P, Chao J. Efficacy and safety of adalimumab in Canadian patients with moderate to severe Crohn's disease: results of the adalimumab in Canadian subjects with moderate to severe Crohn's disease (ACCESS) trial. Can J Gastroenterol. 2011;25:419-25.

20. Sandborn WJ, Hanauer SB, Rutgeerts P, Fedorak RN, Lukas M, MacIntosh DG, Panaccione R, Wolf D, Kent JD, Bittle B, Li J, Pollack PF. Adalimumab for maintenance treatment of Crohn's disease: results of the CLASSIC II trial. Gut. 2007:56:1232-9.

21. Sandborn WJ, Rutgeerts P, Enns R, Hanauer SB, Colombel JF, Panaccione R, D'Haens G, Li J, Rosenfeld MR, Kent JD, Pollack PF. Adalimumab induction therapy for Crohn's Disease previously treated with infliximab. A Randomized trial. Ann Intern Med. 2007;146:829-38.

22. Schreiber S. Certolizumab pegol for the treatment of Crohn's disease. Therap Adv Gastroenterol. 2011;4:375-89.

23. Steinhart AH, Ewe K, Griffiths AM, Modigliani R, Thomsen OO Corticosteroid for maintenance of remission in Crohn's disease. Cochrane Database Syst Rev. 2003;4:CD000301

24. Swoger JM, Loftus EV, Tremaine WJ, Faubion WA, Pardi DS, Kane SV, Hanson KA, Harmsen WS, Zinsmeister AR, Sandborn WJ. Adalimumab for Crohn's disease in clinical practice at Mayo clinic: the first 118 patients. Inflamm Bowel Dis. 2010;16:1912-21.

25. Teixeira FV, Hossne RS. Terapia biológica na doença inflamatória intestinal. In: Cardozo WS, Sobrado CW. Doença inflamatória intestinal. Barueri: Manole, 2012. p. 241-54.

26. Victoria CR, Sassak LY, Nunes HR. Incidence and prevalence rates of inflammatory bowel diseases, in midwestern São Paulo State, Brazil. Arq Gastr. 2009;46:20-5. 